\title{
Financial Statements Insurance
}

\author{
Alex Dontoh \\ Joshua Ronen \\ Bharat Sarath \\ New York University \\ New York University \\ Baruch College
}

August 17, 2004 


\section{Introduction}

The largest corporate bankruptcy filed in the U.S., that of Enron in 2001, was preceded by a string of disclosures about errors in and corrections to their financial statements. ${ }^{1}$ The presence of such errors highlights the fact that market participants face two inter-related problems when pricing securities based on financial statements. First, they must assess the quality of the information contained in the financial statements. Then, they must actually make projections about the future. The second is to actually make projections about future cash flows and to fold these projected cash flows back into a value for the security. Even if one assumes that accurate models are available for projecting cash flows and valuing securities, uncertainty about the quality of the financial statements can lead to pricing distortions and inefficient market allocations.

Several causes have been suggested for the current state of affairs. Most important, perhaps, are managers' tendency to inflate stock prices for personal gain through deceit, 'cooking the books'- misrepresentations in financial reporting - and other unethical behavioral practices, and auditors' failure to fulfill their role as independent gatekeepers. Currently, the incentives driving auditors' behavior may not elicit unbiased reports. Auditors are paid by the companies they audit which creates an inherent conflict of interest that is endemic to the relation between the firm (the principal) and the auditor (the agent).

Unfortunately, remedying these problems is not simple. Prosecution and punishment may not adequately deter wrongdoing, as intentional misrepresentation is difficult to discover or prove. Overhauling the regulatory structure and adding layers of supervision and monitoring by the government would be inefficient and socially wasteful. In addition, little can be

\footnotetext{
${ }^{1}$ As catastrophic as this event may have been, it proved to be only the beginning of a series of stunning revelations of accounting irregularities by major corporations that were the darlings of Wall Street: Worldcom, AOL, Metromedia Fiber Networks, Qwest Communications; the list goes on and on. The number of restatements keeps rising, from 50 a year in the early 1990s to well over 200 a year in 2001 .
} 
done in the short run to cultivate ethical personalities. Rather, the solution lies in market mechanisms that eliminate the perverse incentives of gatekeepers, most notably the auditors. We need an institutional mechanism that eliminates the conflict of interest auditors face and properly align their incentives with those of shareholders.

We present here a financial statement insurance mechanism that promotes improved alignment of incentives, and hence better quality audits. We show analytically that the introduction of financial statement insurance can significantly mitigate market inefficiencies arising from uncertainty regarding the quality of financial statements. ${ }^{2}$ The basic structure of Financial Statement Insurance (FSI) can be described as follows (details may be found in Appendix 2, based on Ronen (2002)). Instead of appointing and paying auditors, companies would purchase financial statement insurance that provides coverage to investors against losses suffered as a result of misrepresentation in financial reports. The insurance coverage that the companies are able to obtain is publicized, as are the premiums paid for that coverage. The insurance carriers would then appoint - and pay - the auditors, who attest to the accuracy of the financial statements of the prospective insurance clients. Those firms announcing higher limits of coverage and smaller premiums would distinguish themselves in the eyes of the investors as companies with higher quality financial statements. In contrast, those with smaller or no coverage or higher premiums will reveal themselves as those with lower quality financial statements. Every company will be eager to get higher coverage and pay smaller premiums lest it be identified as the latter. A sort of Gresham's law in reverse would be set in operation, resulting in a flight to quality.

Before addressing the economic consequences arising from financial statement insurance and related procedural changes, we present arguments suggesting that a critical economic

\footnotetext{
${ }^{2} \mathrm{An}$ analogy is the product warranty market. Grossman (1981) shows that managers use full disclosure of private information to maintain the value of the product they sell. When managers do not disclose, buyers or investors discount the price to reflect their expectations of hidden information about low product quality.
} 
factor in the recent debacles was the misaligned incentives of the auditors. In particular, a coincidence of circumstances created an environment within which the misaligned incentives of the auditors brought about a disastrous failure in the gate keeping function and a consequent misallocation of capital.

In the current social arrangement, auditors face a conflict of interest. They are paid by the companies they audit and look to the CEOs and CFOs of the same company to facilitate their continued engagement. According to sound principles of corporate governance, auditors are supposed to be the agents of the shareholders, but in practice, it is management that hires the auditor. Although shareholders vote on management's recommendation of which auditor to hire, the decision is in practice made by management. This arrangement creates an inherent conflict of interest for the auditor. It is the management of the company that engages the auditor and ultimately pays for the services and hence determines auditing and consulting fee structures to elicit actions, including opinions and assurances, that it desires from the auditor. The risk of losing fees from a long-term audit engagement - even in light of the limitations on non-audit services imposed by the Sarbanes-Oxley Act of 2002 - effectively guarantees that the auditor complies with management's wishes.

It is altogether clear that in the current institutional setting, the anticipation of potential gains from acquiescing in management's wishes more than offsets the threat of legal liability against auditors from shareholder class action suits. Furthermore, a large proportion of shareholder recoveries in audit failure-related class action suits are paid out of corporations' own resources. Ironically, such recoveries diminish the wealth of shareholders who purchased the shares at prices potentially inflated as a result of misrepresentations even further due to deadweight losses arising from the cost of defending the suit. It is tempting to suggest that an increase in the liability exposure of the auditors can deter malpractice but this falls short on two grounds. First, it fails to address the misallocation of risk and resources. Imposing 
higher litigation penalties on the auditor ex post does not enhance the ability of society to distinguish, ex ante, between firms with intrinsically high returns and the Enrons and Worldcoms of the world which have intrinsically low or negative returns but misrepresent themselves as high-return firms. Second, increasing exposure to liability and instituting high legislated penalties may drive auditors out of the business of auditing altogether. Again, not a welcome prospect.

To summarize, under the existing regime, penalties on the auditor are effectively reimbursed by the client and consequently have no incentive effect for the auditor. The auditor is prepared to allow statements of low quality to be released to the market because the value of the ongoing engagement outweigh the effects of liability. Even if penalties are increased, they will typically be applied after the misallocation of capital takes place and draconian penalties may kill off the audit industry. Further, the costs of suing auditors is high, so only the most egregious cases will find their way into a court of law. Low probability of detection and punishment combined with high penalties distort incentives for providing high-quality financial statements. To the extent that information about financial statement quality does not get impounded in prices, there is less of an incentive to improve this quality ex-ante.

In proposing Financial Statement Insurance, we argue that the imperfect alignment of interests between managers and shareholders and the intractable conflict of interest imposed on auditors cannot be rectified through legislation, regulation, enforcement, or litigation. Instead, what is needed is an agency relationship between the auditor and an appropriate principal, whose economic interests are solely aligned with the goal of promoting the quality of the financial statement. In other words, there is the need to align the interest of shareholders with the auditor's reward structure through an intermediary who does not benefit from the price at which securities are traded. ${ }^{3}$ In the context of a free market mechanism,

\footnotetext{
${ }^{3}$ Such a realignment of interests would contribute to restoring the "complete fidelity to the public's trust" that Chief Justice Burger insisted on in a celebrated opinion: "By certifying the public reports that collectively depict a corporation's financial
} 
insurance carriers can serve the role of such an intermediary. The critical features of the FSI scheme underlying this study are the following:(i)the effect of publicizing the premium charged to different firms; and (ii)the shift of control over the auditor's compensation and, hence, incentive structure from management to the insurer. We seek to formalize these two features and to demonstrate that FSI, when linked with appropriate disclosure provisions, leads firms to improve the quality of their disclosures voluntarily.

In Section 2, we develop a formal model for analyzing the link between economic efficiency and the quality of the financial statement. We then examine the consequences of allowing signaling through the insurance premium. In Section 4, we examine the consequences of making the auditor an agent of the insurance-carrier rather than management under an assumption that the auditor acts as an individual utility maximizer. Section 5 contains our conclusions. .

\section{Model}

We develop a model in which firms try to attract capital through their financial reports. The basic framework is one in which a firm's management invariably benefits from obtaining capital, but there is a social loss if low rate of return projects are funded. ${ }^{4}$ We consider an economy with $N$ firms, where each firm has $L$ possible rates of return $r_{1}<r_{2}<\ldots<r_{L}$. We shall refer to a firm with rate-of-return $r_{i}$ as being of type $i$. The rates of return for each firm $f$, denoted by $r_{f}$, is drawn randomly by nature at the start of the period and is independent of other firms. In addition, we assume that there is a minimum threshold rate, $r^{*}$, such that

status, the independent auditor assumes a public responsibility transcending any employment relationship with the client. The independent public accountant performing this special function owes ultimate allegiance to the corporation's creditors and stockholders, as well as to the investing public. This "public watchdog" function demands that the accountant maintain total independence from the client at all times and requires complete fidelity to the public trust" [465 U.S. 805, 818].

${ }^{4}$ More generally, it is possible to consider a multi-period consumption-investment model where investing in some of the projects reduces overall welfare calculated across several periods. 
funding firms with rates of return less than $r^{*}$ results in a social loss. $r^{*}$ represents the social cost of capital and is assumed to be independent of firm's rates of return. We assume that $r^{*}>r_{1}$ so that funding projects randomly results in some expected social loss. In the firstbest scenario, in which each firm's rate of return is perfectly inferred, only firms with rates of return higher than $r^{*}$ will obtain capital. In a second-best scenario, however, in which investors do not know each firm's type, investors decide whether to allocate capital to firm $f$ based on its financial report, denoted by $\theta_{f}$. Investors analyze the report, $\theta_{f}$, and fund firm $f$ if the implied rate-of-return, $\hat{r}_{f}$, is greater than the threshold rate $r^{*}$. The problem faced by investors is that firms have the ability to strategically bias financial reports and obtain capital even when $r_{f}<r^{*}$.

The managers of a firm typically benefit in both pecuniary and non-pecuniary ways from capital inflows; we represent the benefit of capital inflows to management by a parameter $B$, for benefits. In other words, by ensuring a capital inflow, the firm's management generates both a return $r_{f}$, which is passed back to shareholders and a benefit $B$ for themselves. ${ }^{5}$ The manager's goal in our model is to maximize potential benefits to themselves by convincing investors to provide capital.

The strategic tool for obtaining capital is an audited financial report that is issued to investors. Although this report may not be directly falsified, it can be manipulated indirectly through a reduction in the quality of the statements. ${ }^{6}$ At the start, the managers of firm $f$ are assumed to obtain a private signal, $\omega_{f}$, about their future rates of return. We denote by

\footnotetext{
"We use the term "capital inflow" and henceforth also "funding" in a broad sense to include any purchases of the firm's stock by investors - whether in a public offering or in secondary trading. In the latter case, the purchase of stock exerts an upward pressure on its price thereby decreasing the firm's cost of capital. The firm would be able to finance investment projects that it could not afford without the price increase (price inflation in the case of misrepresentation). For example it can do so by selling treasury stock at the higher price, obtaining debt financing at lower cost due to a lower debt-equity ratio, etc.; management, as well, benefits through the increased value of stock and options holdings.

${ }^{6}$ A typical example may be the choice of classifying a capital lease as an operating lease by using a higher than warranted discount rate.
} 
the symbol $P\left(i \mid \omega_{f}\right)$ the probability that the realized rate of return will be $r_{i}$ for a firm, $f$ that receives a private signal, $\omega_{f}$. Based on their private signal, the firm's manager chooses accounting policies that may increase or decrease their financial statement quality (FSQ) denoted by the parameter $\mathbf{x}$. After the firms' rate of return is realized, the financial report $\theta_{f}$, is issued by firm $f$ to investors. The inferred rate of return contingent on the report depends on the quality $\mathbf{x}$.

In our formulation, the lower the quality of financial statements, the greater the probability that the firm's rate of return is misinterpreted. To arrive at this feature, we introduce two parameters that determine financial statement quality.

\section{Assumption 1 (Determinants of FSQ)}

$F S Q$ is determined by two parameters, $\mathbf{q} \in \mathbf{Q}$ and $\mathbf{e} \in \mathbf{E}$ where $\mathbf{Q}$ and $\mathbf{E}$ denote closed bounded cubes in $\Re^{A}$ and $\Re^{B}$ respectively. $\mathbf{q}$ is chosen by the firm and $\mathbf{e}$ by the auditor. We write $\mathbf{X}=\mathbf{Q} \times \mathbf{E}$ and use the symbol $\mathbf{X}$ to denote the pair $(\mathbf{q}, \mathbf{e})$.

The next step is to link $\mathbf{x}$ (and thereby, $\mathbf{q}$ and $\mathbf{e}$ ) with the probability distribution of how firms are represented relative to their true type. Let $P(j \mid i, \mathbf{x})$ represent the probability that a firm $f$ of type $i$ receives a report $\theta_{f}=j$ (that is, a report implying a return of $r_{j}$ ) under FSQ $\mathbf{x}$. We assume that all errors are one-sided; that is, a firm $f$ of type $i$ only receives reports $\theta_{f}=j \geq i .^{7}$ The key step is to describe how $P(j \mid i, \mathbf{x})$ changes in quality $\mathbf{x}$.

We begin by noting that our parameter set, $\mathbf{X}=\mathbf{Q} \times \mathbf{E}$, representing quality, has a natural component wise partial order; that is, for $\mathbf{x}, \mathbf{y} \in \mathbf{X}, \mathbf{y} \preceq \mathbf{x}$ if and only if every component of $\mathbf{x}$ is greater than the corresponding component of $\mathbf{y}$. In terms of the probability distribution $P(j \mid i, \mathbf{x})$, a reduction in quality ought to "increase" the level of overstatement. The notion of "increase" in a probability distribution is captured by of first-degree stochastic

\footnotetext{
${ }^{7}$ Recall that at the time of the report, firms know their true rate of return. The idea is that firms will correct any downside error by providing correct information about their type but will allow overstatements to proceed uncorrected.
} 
dominance(hereafter, FDSD). The next assumption links the natural partial order on our quality parameter with the partial order of FDSD on distributions.

\section{Assumption 2 (FSQ and First-Degree Stochastic Dominance)}

The probability of overstatement increases in the sense of first-degree stochastic dominance (hereafter, FDSD) as FSQ decreases. More formally, for a given type $i$

(1) $P(j \mid i, \mathbf{y}) F D S D$ 's $P(j \mid i, \mathbf{x})$ whenever $\mathbf{y} \preceq \mathbf{x}$.

In addition, we shall make the further structural assumption that higher signals are "good news" :

(2) For a given quality $\mathbf{x}, \frac{P(j \mid i, \mathbf{x})}{P(j \mid k, \mathbf{x})}$ is increasing in $j$ whenever $i \geq k$,

and that lower quality makes it harder to separate firms through their reports, that is,

(3) For any two types $i, k$ with $i>k$ and two FSQ levels $\mathbf{y} \preceq \mathbf{x}$, it is harder to separate $i$ and $k$ through their reports at the lower FSQ $\mathbf{y}$ than at the higher FSQ $\mathbf{x}$. In distributional terms this is expressed as:

$$
\sum_{j=l}^{L}\{P(j \mid i, \mathbf{x})-P(j \mid k, \mathbf{x})\} \quad \geq \quad \sum_{j=l}^{L}\{P(j \mid i, \mathbf{y})-P(j \mid k, \mathbf{y})\} \quad \text { for every } l \geq k
$$

Assumption (1) sums up the major formal content of the definition, that is, lower FSQ translates to increased misinterpretation in the sense of FDSD. Assumption 2 imposes an intuitive restriction on the relationship between the true rate of return and the financial reported value. The relationship asserts that higher signals are "good news" about types in the sense of Milgrom [?]. (3) strengthens (1); indeed, when there are only two types and $i=2, k=1,(3)$ is reduced to the requirement that $P(2 \mid 1, \mathbf{y})>P(2 \mid 1, \mathbf{x})$ which is exactly the same as (1). With multiple types, more regularity in the way that the weights shift to the upper tails is needed. (3) states that the relative weight in the upper tail converges for all types as FSQ is reduced. 
Although Assumption 2 captures the reporting technology, investor inferences are affected by an additional consideration. The central behavioral premise underlying our formulation is that firms can strategically use low-quality financial statements to mislead investors. ${ }^{8}$ Because financial statement quality is unobservable and may be strategically manipulated, (Bayesian) rational investors will form conjectures regarding this quality. Upon observing a financial statement investors will assign some probability that the statements are, in fact, misleading. This "scepticism" will be based on priors regarding FSQ. Denote these priors by $\vec{\nu}=\left\{\nu_{1}, \nu_{2}, \ldots, \nu_{L}\right\}$; investors believe that a firm with private signal $\omega_{l}$ issues financial statements of quality $\nu_{l} .{ }^{9}$ The inferred distribution of types based on beliefs $\vec{\nu}$ and a report $\theta_{f}=j$ is denoted by $P\left(i \mid \theta_{f}=j, \vec{\nu}\right)$ or $P(i \mid j, \vec{\nu})$ for simplicity. Consider this distribution for a firm that receives a private signal $\omega_{l}$. Such a firm will choose some (optimal) quality level $\mathbf{x}_{k}=\mathbf{x}\left(\omega_{l}\right)$. The firm will then have a realized rate of return of $r_{i}$ with probability $P\left(i \mid \omega_{l}\right)$. In turn, this rate of return will be overstated as $\theta_{f}=j \geq i$ with probability $P\left(j \mid i, \mathbf{x}_{f}\right)$.

Investors will try to reverse this process. Upon seeing a report $\theta_{f}=j$, they will assign some probability that the firms private signal was $\omega_{l}$. Then, using their beliefs regarding the FSQ chosen by this type of firm, $\nu_{l}$, they will form posterior probabilities, $P(i \mid j, \vec{\nu})$, that the rate of return would be $r_{i}$. They will then calculate an expected rate of return, $E\left[r \mid \theta_{f}, \vec{\nu}\right]$ for firm $f$.

In order to perform this calculation, we first observe that the joint probability distribution

\footnotetext{
${ }^{8}$ Of course, the use of misleading financial statements opens the firm to potential liability. Therefore, lower quality should lead to a greater probability of overestimating the rate of return as well as higher liability. The benefits of acquiring capital through a misleading financial statement must be balanced against the legal exposure in determining the optimal FSQ level.

${ }^{9}$ Given our assumption that firm types are drawn independently, all firms with the same private signal $\omega_{l}$ face identical decision problems regarding optimal implementation of quality. We simplify the belief structure by assuming that each firm with a given private signal $\omega_{l}$ has a single quality choice assigned to it. A more general formulation would set the perceived quality $\nu_{l}$ to be a measure on $\mathbf{Q} \times \mathbf{E}$.
} 
of $i, \omega_{l}, j$ is as follows:

$$
P\left(i, \theta_{f}=j, \omega_{l}, \mathbf{x}\right)=P(j \mid i, \mathbf{x}) P\left(i, \omega_{l}\right)=P(j \mid i, \mathbf{x}) P\left(i \mid \omega_{l}\right) P\left(\omega_{l}\right)
$$

Equation (1) states that once the type, $i$, is realized, the probability of report $j$, is determined by the actual value of $i$ and the FSQ $\mathbf{x}$, and is independent of the earlier imperfect signal $\omega_{l}$. Built into this equation is the fact that the joint distribution of $i$ and $\omega_{l}$ is unaffected by the choice of $\mathbf{x}$ - that is, the financial reporting choice affects only the reported rate of return and not the actual rate of return, $r_{i}$. It follows that $P\left(i, j \mid \omega_{l}, \mathbf{x}\right)=P(j \mid i, \mathbf{x}) P\left(i \mid \omega_{x}\right)$ and that:

$$
P\left(i \mid \theta_{f}=j, \omega_{l}, \mathbf{x}\right)=\frac{P(j \mid i, \mathbf{x}) P\left(i \mid \omega_{l}\right)}{\sum_{i=1}^{L} P(j \mid i, \mathbf{x}) P\left(i \mid \omega_{l}\right)}
$$

Using (2) and the (prespecified) beliefs $\vec{\nu}$, the expected rate of return for a firm that originally received (an unknown) private signal $\omega_{l}$ and has reported $\theta_{f}=j$ is given by:

$$
E\left[r \mid \theta_{f}=j, \omega_{l}, \vec{\nu}\right]=E\left[r \mid \theta_{f}=j, \omega_{l}, \nu_{l}\right]=\frac{\sum_{i=1}^{L} r_{i} P\left(j \mid i, \nu_{l}\right) P\left(i \mid \omega_{l}\right)}{\sum_{i=1}^{L} P\left(j \mid i, \nu_{l}\right) P\left(i \mid \omega_{l}\right)}
$$

Finally, the expected rate of return for an arbitrary firm $f$ reporting $\theta_{f}=j$ is the expectation of (3) over the probability distribution

$E\left[r \mid \theta_{f}=j, \vec{\nu}\right]=\sum_{l=1}^{L} E\left[r \mid \theta_{f}=j, \omega_{l}, \vec{\nu}\right] P\left(\omega_{l}\right)=\sum_{l=1}^{L}\left\{\frac{\sum_{i=1}^{L} r_{i} P\left(j \mid i, \nu_{l}\right) P\left(i \mid \omega_{l}\right)}{\sum_{i=1}^{L} P\left(j \mid i, \nu_{l}\right) P\left(i \mid \omega_{l}\right)}\right\} P\left(\omega_{l}\right)$

At this stage, we make the important qualitative observation that all firms that issue a particular report $\theta_{f}=j$ are assigned the same inferred expected rate of return. We contrast this with the situation where in addition to a financial report, $\theta_{f}$, firms also report their insurance premium, $\pi_{f}$.

Denoting the inferred rate of return under beliefs $\vec{\nu}$ conditional on both report and premium by $E\left[r \mid \theta_{f}=j, \pi_{f}, \vec{\nu}\right]$, we obtain:

$$
E\left[r \mid \theta_{f}=j, \vec{\nu}, \pi_{f}\right]=\sum_{l=1}^{L} \sum_{l=1}^{L}\left\{\frac{\sum_{i=1}^{L} r_{i} P\left(j \mid i, \nu_{l}\right) P\left(i \mid \omega_{l}\right)}{\sum_{i=1}^{L} P\left(j \mid i, \nu_{l}\right) P\left(i \mid \omega_{l}\right)}\right\} P\left(\omega_{l} \mid \pi_{f}, \vec{\nu}\right)
$$


The key difference between (4) and (5) is that the premium reveals something about the FSQ, and this in turn is reflected in the inferred rate of return through a posterior probability distribution about the private signal types that will end up with that premium. To illustrate further, suppose that a firm with the lowest private signal type $\omega_{1}$ is assumed to choose a low FSQ $\nu_{1}$ with a resulting premium $\pi_{1}$. Then, conditional on observing that firm $f$ has been offered a low premium $\pi_{f}<\pi_{1}$, the probability weight $P\left(\omega_{1} \mid \pi_{f}, \vec{\nu}\right)=0$. In other words, firms will be able to reveal their private signals through their reported premiums and thereby affect the inferred report-contingent rate of return.

The inferred rate of return for firm $f$ depends on beliefs $\vec{\nu}$ and can differ from the actual distribution, $P\left(i \mid j, \mathbf{x}_{f}\right)$. However, we impose the condition that in-equilibrium, $\nu_{k}=\mathbf{x}\left(\omega_{k}\right)$ where $\mathbf{x}\left(\omega_{k}\right)$ denotes the FSQ implemented by a firm with private information $\omega_{k}$. This is an important point that needs to be emphasized. Firms have the ability to distort the perceived level of FSQ but this is not a stable "equilibrium" situation. For an equilibrium to be sustainable, it must be optimal for firms and auditors to set FSQ levels that are consistent with investor beliefs.

\subsection{Liability Structure}

Both firms and auditors face penalties under provisions of the 1933 and 1934 Securities

Acts and other statutory and case law when they issue inaccurate financial reports. Such penalties act both to increase the quality of financial statements and to provide some level of compensation to investors. For the purposes of analysis, we assume that the coverage under the proposed FSI scheme is the same as the expected recovery under the current institutional arrangements. In general, FSI permits more direct and less restrictive coverage than the penalties imposed by the Securities Acts. That is, FSI directly insures investors against misrepresentations in the financial statements; under the present regime, on the other 
hand, insurance is "indirect" as it covers the liability of directors and auditors. Aspects of the FSI scheme outlined in Ronen (2002) that are not addressed in our formal analysis are discussed in Section 4.

Recall that the lower the FSQ, the greater the probability that the financial report will imply too high a rate of return. Because a firm is liable for penalties whenever its financial statements are deemed to be misleading, we model liability simply as a function of the FSQ choices. The firm's expected liability is denoted by $\mathcal{L}_{f}(\mathbf{q})$ and the auditor's expected liability by $\mathcal{L}_{a}(\mathbf{q}, \mathbf{e})$. Implicit in this notation is the legal structure, because the firm is liable only for its quality choice but auditors are liable for both poor quality statements issued by the firm and their own level of quality improvement (represented by the choice of $\mathbf{e}$ ). The only structure we impose is the following:

(1) $\mathcal{L}_{f}(\mathbf{q})$ decreases in $\mathbf{q}$ (under the usual partial order on $\mathbf{q}$ ) and $\mathcal{L}_{a}(\mathbf{q}, \mathbf{e})$ decreases in both $\mathbf{q}$ and $\mathbf{e}^{10}$

(2) The cross-partial $\frac{\partial^{2}}{\partial e_{i} \partial q_{j}}\left(\mathcal{L}_{a}(\mathbf{q}, \mathbf{e})\right)<0$ for every $i, j$, that is, the marginal effect of an increase in audit quality on liability is less if the firm has already implemented a higher quality (and the auditor faces lower liability).

This second assumption is needed to set up a monotone relationship between the firm's choice of quality and the overall FSQ obtained as a combination of both $\mathbf{q}$ and $\mathbf{e}$ choices (see Lemma 3).

\section{$3 \quad$ Results}

The main focus of our formal analysis is to establish two results:

\footnotetext{
${ }^{10} \mathrm{We}$ are realistically mindful of the fact that liability for erroneous disclosures exists even when the firm does not attract additional capital. Indeed, as long as the firm's securities are publicly traded, it faces potential liability under the 1934 Securities Act.
} 
(1) To show that a public disclosure of the insurance premium charged on the financial statement increases the efficiency of capital allocation; and

(2) To show that switching the audit employment contract to the insurer in addition to disclosing the premium increases both the quality of financial reporting and the efficiency of capital allocation.

We begin by motivating the first result through an example. In order to make the example as simple as possible, we suppress the role of the auditor and assume that the insurer can observe the quality of the financial statement costlessly.

\section{An Example}

First, we assume that there are $N$ firms each of which can have two possible rates of return, i.e., that there are two types $(\mathrm{L}=2)$. In addition, we assume that the quality variable, $q$, is one-dimensional and lies in $[0, \bar{q}]$, where $\bar{q}<1$. Next, we assume that the private information is perfect. $\omega_{l}=1,2$ reveals the expected rate of return as $r_{i}$ and eliminate the role of the auditor by setting $P(i \mid i, q, \mathbf{e})=q$ for $i=1,2$. That is, with FSQ $q$, the probability that the

firm's type is reported correctly is $q$, and, as there are only two types, the probability of the firm being misclassified is $1-q$. Let the beliefs of investors be represented by $\nu_{i}$; the firm that receives a private signal that it's rate of return is $r_{i}$ is expected to set its FSQ at $\nu_{i}$. Assuming that each firm-type is equally probable, the inferred rates-of return are as follows:

$$
\begin{aligned}
& \hat{r}_{2}=E\left[r \mid \theta_{f}=2\right]=\frac{r_{1}\left(1-\nu_{1}\right)+r_{2}}{\left(1-\nu_{1}\right)+1}=\frac{1-\nu_{1}}{2-\nu_{1}} r_{1}+\frac{1}{2-\nu_{1}} r_{2} \\
& \hat{r}_{1}=E\left[r \mid \theta_{f}=1\right]=r_{1}
\end{aligned}
$$

It follows that the funding probability from picking FSQ level $q$ for a firm that receives private signal $\omega_{f}=1$ is given by:

$$
F P(q, 1)=q F\left(\hat{r}_{1}\right)+(1-q) F\left(\hat{r}_{2},\right)
$$


where $F$ denotes the distribution function of $r^{*}$. Because $\hat{r}_{2}>\hat{r}_{1}$, it follows that the funding probability is strictly decreasing in $q$ for every type 1 firm. In contrast, a firm with private signal $\omega_{f}=2$ has a realized rate of return 2 and its funding probability is unaffected by the choice of $q$ (because it's type cannot be overstated).

If the benefits of funding are sufficiently high, the firm with a low private signal will set $q_{1}^{*}=0$. It therefore is always reported as $\theta=2$, and it follows from Equation 6 that, in equilibrium, where $\nu_{1}=q_{1}^{*}=0, \hat{r}_{2}=\left(r_{1}+r_{2}\right) / 2$. In this setting, the social loss arises because firms with low rates of return are funded even though they lie below the opportunity cost $r^{*}$ and high rates of return firms are funded too infrequently. The two components of the loss (per unit of capital) are given as follows:

(1) $\int_{r_{1}}^{\left(r_{1}+r_{2}\right) / 2}\left(r^{*}-r_{1}\right) f\left(r^{*}\right) d r^{*}$ because low-type firms are funded and

(2) $\int_{\left(r_{1}+r_{2}\right) / 2}^{r_{2}}\left(r_{2}-r^{*}\right) f\left(r^{*}\right) d r^{*}$ because high-type firms are not funded.

The total social loss may then be written as:

$$
\int_{r_{1}}^{r_{2}} \min \left\{r^{*}-r_{1}, r_{2}-r^{*}\right\} f\left(r^{*}\right) d r^{*}
$$

In contrast, consider the case where the firm's choice of FSQ is known to the insurer who then sets a premium based on the level of coverage. We shall assume that the cost of coverage is strictly decreasing in quality, that is, $\pi(q)$ is decreasing in $q$. In this example, the following is seen to be an equilibrium:

- Both Firm types choose FSQ $q=\bar{q}$, i.e., the highest quality financial statement, and pay the associated (low) insurance premium $\pi(\bar{q})$.

- Any firm that is observed to have a premium $\pi>\pi(\bar{q})$ is classified as a type-1 firm.

To see that this represents an equilibrium, let $q_{1}^{*}$ represent the equilibrium FSQ choice of Firm $f$ that has received private signal $\omega_{1}$; either $q_{1}^{*}<\bar{q}$ or $q_{1}=\bar{q}$. If, $q_{1}^{*}<\bar{q}$, the premium 
rate for firm $f, \pi\left(q_{1}^{*}\right)>\pi(\bar{q})$, and its inferred rate of return is $r_{1}$ irrespective of the report. Therefore, it's probability of funding is $F\left(r_{1}\right)$. If however, Firm $f$ mimics the high privatesignal firm and sets $q_{1}^{*}=\bar{q}$, the inferred rates of return are given by

$$
\begin{aligned}
& \bar{r}_{2}=E\left[r \mid \theta_{f}=2\right]=\frac{r_{1}(1-\bar{q})+r_{2}}{(1-\bar{q})+1}=\left[\frac{1-\bar{q}}{2-\bar{q}}\right] r_{1}+\left[\frac{1}{2-\bar{q}}\right] r_{2} \\
& \bar{r}_{1}=E\left[r \mid \theta_{f}=1\right]=r_{1}
\end{aligned}
$$

and the probability of funding increases by $(1-\bar{q})\left[F\left(\bar{r}_{2}\right)-F\left(r_{1}\right)\right]$ (i.e., by the higher probability of funding when the firm is reported as "type-2."). Note that the social loss now becomes::

(1) $(1-\bar{q}) \int_{r_{1}}^{\bar{r}_{2}}\left(r^{*}-r_{1}\right) f\left(r^{*}\right) d r^{*}$ because low-type firms are funded and

(2) $\int_{\bar{r}_{2}}^{r_{2}}\left(r_{2}-r^{*}\right) f\left(r^{*}\right) d r^{*}$ because high-type firms are not funded.

with attendant social loss:

$$
\int_{r_{1}}^{r_{2}} \min \left\{(1-\bar{q})\left(r^{*}-r_{1}\right), r_{2}-r^{*}\right\} f\left(r^{*}\right) d r^{*}
$$

Any $r^{*} \leq \bar{r}_{2}$ can be written as a convex combination $\lambda r_{1}+(1-\lambda) r_{2}$ with $\lambda \geq(1-\bar{q}) /(2-\bar{q})$; it follows that for $r^{*} \leq \bar{r}_{2}$,

$$
\begin{aligned}
(1-\bar{q})\left(r^{*}-r_{1}\right) & =(1-\bar{q})(1-\lambda)\left(r_{2}-r_{1}\right) \leq(1-\bar{q})\left(1-\frac{1-\bar{q}}{2-\bar{q}}\right)\left(r_{2}-r_{1}\right)=\frac{1-\bar{q}}{2-\bar{q}}\left(r_{2}-r_{1}\right) \\
& \leq \min \left\{r^{*}-r_{1}, r_{2}-r^{*}\right\}
\end{aligned}
$$

A comparison of (9) and (10) shows that the social loss is reduced through the provision of FSI.

Notice in this example that if a firm with private signal $\omega_{f}=1$ sets $q_{1}<\bar{q}$, then the best response for the firm with the high private signal is to set $q_{2}=\bar{q}$ - this separating policy leads to funding with probability $F\left(r_{2}\right)$ at a minimum insurance cost. if, however, the firm with the high private signal sets $q_{2}=\bar{q}$, the best strategy for a firm with low private signal 
is to "mimic" and set $q_{1}=\bar{q}$. Mimicry increases the funding probability (and leads to the equilibrium described above). In contrast, when the type- 1 firm sets $q_{1}=\bar{q}$ and the type- 2 firm sets $q_{2}<\bar{q}$ the situation is untenable in equilibrium because by increasing $q$ slightly, the type-2 firm reduces insurance costs but still separates itself from the type- 1 firm. Thus, $q_{1}=\bar{q}, q_{2}<\bar{q}$ should never be an equilibrium. Hence, the only plausible equilibrium is for both firms to set $q_{i}=\bar{q}$. We shall return to this point formally in Proposition 4 .

This example does not incorporate a role for the auditor, but a little reflection shows that the core intuition survives in a more complex setting where reports are influenced by an auditor acting under moral hazard. In particular, if the income of the auditor is determined by the insurer, sufficient incentives may be provided to elicit truthful revelation regarding the FSQ. Once FSQ is known (perhaps imperfectly) to the insurer, premium levels reveal this information to investors. In particular, when firms defect from the anticipated level of FSQ, that is, if a firm has been charged a premium $\pi_{f}$ higher than anticipated, investors find out about this before trading. We are then essentially back in the situation discussed in the example.

The example has the characteristics of a signaling model where firms are separated out through the level of the insurance premium. Yet, there is an important difference. In a standard signaling model, the differential costs of signals across types arise from an exogenous factor related to type. In contrast, in the setting of the example, the cost of signals differs across types because of an endogenous factor - the reaction of providers of capital. For this reason, the initial beliefs of investors play a significant role in the analysis.

Let $\left\{\nu_{1}, \nu_{2}\right\}=\vec{\nu}$ represent the beliefs of investors. In this example, the expected return on the high report, $\theta=2$, is some weighted average of $r_{2}$ and $r_{1}$ with the weights depending on $\vec{\nu}$; in addition, because Firm 2 always issues report $\theta=2$, the weight on $r_{2}$ is strictly 
positive. In contrast, the report $\theta=1$ necessarily implies that the rate of return is $r_{1}$. Thus, rational investors would fund the report $\theta=2$ with a greater probability than the report $\theta=1$. Our first objective is to establish an analogous result in full generality; that is, we show that the probability of funding increases in the report (Lemma 1), and consequently that it decreases in FSQ (Proposition 1).

\subsection{Funding Probability}

In this section we develop the notation and structure related to the probability that a given firm will obtain funding under FSQ choices q, e. The first result that we establish confirms the plausibility of our information structure. Specifically, we show that higher rates of return are associated with better reports and with higher private signals.

\section{Lemma 1 (Better reports imply higher expected returns)}

For any beliefs $\nu_{f}$ regarding the FSQ of a firm, a higher reported rate of return implies a (strictly) greater inferred rate of return.

\section{Proof:}

Suppose that $k>i$. We have to show that a firm $s$ with report $\theta_{s}=k$ has a higher inferred rate of return than another, $t$, with report $\theta_{t}=i$.

From :

$$
\begin{aligned}
& E_{s}\left[r \mid \theta_{s}=k, \vec{\nu}\right]=\sum_{l=1}^{L}\left\{\frac{\sum_{j=1}^{k} r_{j} P\left(k \mid j, \nu_{l}\right) p\left(j \mid \omega_{l}\right)}{\sum_{j=1}^{k} P\left(k \mid j, \nu_{l}\right) p\left(j \mid \omega_{l}\right)}\right\} p\left(\omega_{l}\right) \\
& E_{t}\left[r \mid \theta_{t}=i, \vec{\nu}\right]=\sum_{l=1}^{L}\left\{\frac{\sum_{j=1}^{i} r_{j} P\left(i \mid j, \nu_{l}\right) p\left(j \mid \omega_{l}\right)}{\sum_{j=1}^{i} P\left(i \mid j, \nu_{l}\right) p\left(j \mid \omega_{l}\right)}\right\} p\left(\omega_{l}\right)
\end{aligned}
$$

Define for $1 \leq j \leq i-1$ :

$$
\xi_{j l}=\frac{P\left(k \mid j, \nu_{l}\right) P\left(j \mid \omega_{l}\right)}{\sum_{t=1}^{k} P\left(k \mid t, \nu_{l}\right) P\left(t \mid \omega_{l}\right)} ; \quad \psi_{j l}=\frac{P\left(i \mid j, \nu_{l}\right) P\left(j \mid \omega_{l}\right)}{\sum_{t=1}^{i} P\left(i \mid t, \nu_{l}\right) P\left(t \mid \omega_{l}\right)}
$$


Define for $j=i$ :

$$
\xi_{i l}=\frac{\sum_{t=i}^{k} P\left(k \mid t, \nu_{l}\right) P\left(t \mid \omega_{l}\right)}{\sum_{t=1}^{k} P\left(k \mid t, \nu_{l}\right) P\left(t \mid \omega_{l}\right)} ; \quad \psi_{i l}=\frac{P\left(i \mid i, \nu_{l}\right) P\left(i \mid \omega_{l}\right)}{\sum_{t=1}^{i} P\left(i \mid t, \nu_{l}\right) P\left(t \mid \omega_{l}\right)}
$$

Note that by definition, $\sum_{j=1}^{i} \xi_{j l}=\sum_{j=1}^{i} \psi_{j l}=1$, that is, $\xi_{j l}$ and $\psi_{j l}$ are probability distributions. Now let $w_{j}=\frac{\xi_{j l}}{\psi_{j l}}$. By Assumption 2 part (1), $w_{j}$ is a strictly increasing function of $j$ for $j \leq i$. Consequently,

$$
\begin{aligned}
E_{s}\left[r \mid \theta_{s}=k, \vec{\nu}\right] & =\sum_{l=1}^{L}\left\{\frac{\sum_{j=1}^{k} r_{j} P\left(k \mid j, \nu_{l}\right) P\left(j \mid \omega_{l}\right)}{\sum_{j=1}^{k} P\left(k \mid j, \nu_{l}\right) P\left(j \mid \omega_{l}\right)}\right\} p\left(\omega_{l}\right) \\
& =\sum_{l=1}^{L}\left\{\sum_{j=1}^{i} r_{j} \xi_{j l}\right\} p\left(\omega_{l}\right)=\sum_{l=1}^{L}\left\{\sum_{j=1}^{i} r_{j} w_{j} \psi_{j l}\right\} p\left(\omega_{l}\right) \\
& >\sum_{l=1}^{L}\left\{\left[\sum_{j=1}^{i} w_{j} \psi_{j l}\right] \times\left[\sum_{j=1}^{i} r_{j} \psi_{j l}\right]\right\} p\left(\omega_{l}\right)=\sum_{l=1}^{L}\left\{[1] \times \sum_{i=1}^{j} r_{j} \psi_{j l}\right\} p\left(\omega_{l}\right) \\
& =E_{t}\left[r \mid \theta_{t}=i, \vec{\nu}\right]
\end{aligned}
$$

For any given firm $f$, the funding probability, $F P_{f}$, depends both on its own report and the realized level of the threshold, $r^{*}$. Firm $f$ will be funded provided that $E\left[r \mid \theta_{f}, \vec{\nu}\right]$ (or, analogously, $\left.E\left[r \mid \theta_{f}=j, \pi_{f}, \vec{\nu}\right]\right)$ is greater than or equal to the cutoff value, $r^{*}$. This probability is, by definition, the value of the cumulative distribution of $r^{*}$ evaluated at $E\left[r \mid \theta_{f}, \vec{\nu}\right]$. To simplify the notation, we set $\hat{r}_{j f}=E_{f}\left[r \mid \theta_{f}=j, \vec{\nu}\right]$ and write $F\left(r^{*}\right)$ for the distribution of $r^{*}$. The funding probability for a firm with private signal $\omega_{k}$ that chooses FSQ $\mathbf{x}$ may then be summarized as in the following lemma.

\section{Lemma 2 (Funding probabilities)}

Denote the probability that a firm $f$ with report $\theta_{f}=j$ will be funded (under beliefs $\vec{\nu}$ ) by $F P_{f}(j \mid \vec{\nu})$ and the total probability across (all reports) under FSQ choice $\mathbf{x}$ by $F P_{f}\left(\mathbf{x} \mid \omega_{l}, \vec{\nu}\right)$. Then:

(1) $F P_{f}(j \mid \vec{\nu})=F\left(\hat{r}_{j f}\right)$ (recall that $F$ is the distribution function of $r^{*}$ and $F\left(\hat{r}_{j f}\right)$ is the probability that $r^{*} \leq \hat{r}_{j f}$.) 
(2) $F P_{f}\left(\mathbf{x} \mid \omega_{l}, \vec{\nu}\right)=\sum_{i=1}^{L}\left\{\sum_{j=i}^{L} F\left(\hat{r}_{j f}\right) P(j \mid i, \mathbf{x})\right\} P\left(i \mid \omega_{l}\right)$

\section{Proof:}

Follows directly from the definitions of $F P_{f}$ and $\hat{r}_{j f}$ and the fact that funding is provided whenever $\hat{r}_{j f} \geq r^{*}$.

The funding probability for any firm $f$ has the following properties:

(1) The component $F P_{f}(j \mid \vec{\nu})$ is dependent on the observed report and beliefs regarding FSQ choices of firms represented by $\vec{\nu}$.

(2) If the firm $f$ realizes rate of return $i$, its report distribution, $P\left(\theta_{f}=j \mid i\right.$, $\left.\mathbf{x}\right)$ is determined by the choice of $\mathbf{x}$.

(3) Based on it's private information $\omega_{l}$, beliefs about other firm's reporting choices $\nu_{-f}$, and litigation cost $\mathcal{L}_{f}(\mathbf{x})$, firm $f$ chooses its level of quality $\mathbf{x}$

The next proposition shows how the probability of funding for firm $f$ changes in the FSQ choices.

\section{Proposition 1 (Funding probability and FSQ choice)}

For any firm $f$ and any beliefs $\vec{\nu}, F P_{f}\left(\mathbf{x} \mid \omega_{l}, \vec{\nu}\right)$ is a strictly decreasing function of $\mathbf{x}$.

\section{Proof:}

Fix any beliefs $\vec{\nu}$. From Lemma 1 and Lemma $(2 ;(1)), F P_{f}(j \mid \vec{\nu})$ is always strictly increasing in reported type $\theta_{f}=j$. It follows from Lemma $(2 ;(2))$ and Assumption $(2 ;(1))$ that the total funding probability, $F P_{f}\left(\mathbf{x} \mid \vec{\nu}, \omega_{l}\right)$, is strictly decreasing in $\mathbf{x}$. 
We now state the formal program for the strategic choice of financial statement quality for a firm $f$ receiving a private signal $\omega_{k}$ (with a non-strategic auditor).

Program I'

$$
\max _{\mathbf{q}, \mathbf{e}, F} \quad F P_{f}\left(\mathbf{q}, \mathbf{e} \mid \omega_{k}, \vec{\nu}_{-f}\right) B-\mathcal{L}_{f}(\mathbf{q})-F
$$

subject to

$$
\begin{aligned}
& U\left(F-\mathcal{L}_{a}(\mathbf{q}, \mathbf{e})\right)-C(\mathbf{e}) \geq \bar{U} \\
& \nu_{i}=\left(\mathbf{q}^{*}, \mathbf{e}^{*}\right)
\end{aligned}
$$

The last equation imposes the requirement that the beliefs about quality agree with the actual optimal choice implemented by the firm of type $i$ in equilibrium. Defining

$$
F(\mathbf{e}, \mathbf{q})=U^{-1}(\bar{U}+C(\mathbf{e}))+\mathcal{L}_{a}(\mathbf{q}, \mathbf{e})
$$

the maximization program may be rewritten as:

$\underline{\text { Program I }}$

$$
\begin{aligned}
& \max _{\mathbf{q}, \mathbf{e}} \quad F P_{f}\left(\mathbf{q}, \mathbf{e} \mid \omega_{k}, \vec{\nu}_{-f}\right) B-\mathcal{L}_{f}(\mathbf{q})-F(\mathbf{q}, \mathbf{e}) \\
& \text { subject to } \\
& \qquad \nu_{i}=\left(\mathbf{q}^{*}, \mathbf{e}^{*}\right)
\end{aligned}
$$

We now turn to the analysis of the situation in which the auditor works for the insurer. In this second setting, the firm again sets the FSQ, $\mathbf{q}$ but the auditor reports $\mathbf{q}$ back to the insurance company. For simplicity, assume that the auditor reports the true value $\mathbf{q}$. Based on this report, the insurance company offers a premium $\pi_{f}$. The insurance premium is revealed to the market along with the financial report. In addition, the insurer implements a level of audit quality e through a suitable incentive scheme. The higher the audit quality implemented, the lower the probability of error.

Denote the observed profile of insurance premiums by $\vec{\pi}$, where $\pi_{f}$ is the premium charged to firm $f$. Let $E\left[r_{f} \mid \theta_{f}, \pi_{f}\right]$ represent the inferred return expected by investors from firm $f$ after observing the report $\theta_{f}$ and an insurance premium $\pi_{f}$. Let $F P_{f}\left(\mathbf{q}, \mathbf{e} \mid \omega_{k}, \vec{\pi}\right)$ denote the 
funding probability expected by a firm $f$ that receives a private signal $\omega_{k}$ and implements FSQ $\{\mathbf{q}, \mathbf{e}\}$. The maximization program for firm $f$ is then given by:

Program II

$$
\begin{aligned}
& \max _{\mathbf{q}, \mathbf{e}, F} \quad F P_{f}\left(q, e \mid \omega_{k}, \vec{\pi}\right) B-\pi_{f} \\
& \text { subject to } \\
& \begin{array}{ll}
\pi_{f}=\min _{e} \mathcal{L}_{f}(\mathbf{q})+F(\mathbf{q}, \mathbf{e}) & (\mathrm{BE}) \\
\nu_{i}=\left(\mathbf{q}^{*}, \mathbf{e}^{*}\right) & (\mathrm{RE})
\end{array}
\end{aligned}
$$

The two main differences between the programs are (i) that the premiums offered to each firm, $\vec{\pi}=\left\{\pi_{1}, \ldots, \pi_{L}\right\}$ are observable; and (ii) the level of audit quality, $e$, is chosen to minimize the total cost to the insurer which consists of the expected claim cost $\mathcal{L}_{f}$ and the audit fee. To maintain notational comparability with Program I, we add the expected litigation cost borne by the auditor to the audit fee. That is, the symbol $F$ denotes the "total audit cost" of service plus the expected litigation cost; in both cases the auditor actually retains the amount $F$ less the expected litigation cost. The premium itself is assumed to be the break- even value for the insurer (constraint $(\mathrm{BE})$ )- a common assumption in the insurance literature.

Because firms and investors are assumed to be risk-neutral, there are no risk-sharing considerations, and insurance does not directly enhance economic efficiency. Rather, the premium functions purely as a signaling device. An important consequence of introducing financial statement insurance relates to the public disclosure of the premium. Such disclosures reveal the quality of the financial statements to investors and make it possible for firms to capture the benefits of implementing high-quality financial systems. In particular, when financial statement insurance premiums are publicly reported, investors can infer which financial statements are truly of high-quality and channel their investments in a more efficient fashion. 


\subsection{Optimal FSQ Choices}

To explain the potential benefits from introducing FSI, we analyze two separate situations:

(i) q, e are directly observable by the insurer, and the premium is based on these observed values; and

(ii) q, e are unobservable by the insurer and the auditor has to be incentivized to report these values truthfully to the insurer.

In each setting, we analyze the consequences of (i) making insurance premiums observable and (ii) switching the auditor from being an agent of the firm to becoming an agent of the insurance company. We analyze two different situations with regard to the auditor's effort because this choice affects the probability of overstatement. Arguably, the firm is privy to whether overstatements take place, and aware of the auditor's correction strategy. In the next section, we drop this assumption and analyze the situation where the auditor's corrective actions are assumed to be unobservable and the auditor is an agent functioning under moral hazard in the classical sense.

\section{Proposition 2 (Equilibrium with uncertainty regarding quality)}

Suppose that the benefits from funding, $B$, are very large relative to the penalties for overstatement - specifically, that the partial derivatives of the liability function in $\mathbf{q}$ and $\mathbf{e}$ satisfy:

$$
\begin{aligned}
& \text { (1) } B>\left\{\frac{\partial}{\partial q}\left(F(\mathbf{q}, \mathbf{e})+\mathcal{L}_{f}(\mathbf{q})\right)\right\}\left\{\frac{\partial}{\partial q}\left(F P_{f}\left(\mathbf{q}, \mathbf{e} \mid \omega_{l}, \vec{\nu}\right)\right)\right\}^{-1} \\
& \text { (2) } B>\left\{\frac{\partial}{\partial e}(F(\mathbf{q}, \mathbf{e}))\right\}\left\{\frac{\partial}{\partial e}\left(F P_{f}\left(\mathbf{q}, \mathbf{e} \mid \omega_{l}, \vec{\nu}\right)\right)\right\}^{-1} .
\end{aligned}
$$

Then the equilibrium quality levels are for every firm to set $q_{f}=\underline{q}$ where $\underline{q}$ is the minimum permissible level and implement $\mathbf{e}=0$. Consequently, capital is allocated to low rate of return firms with relatively high probability. 


\section{Proof:}

From Proposition 1, the condition in the hypothesis of this proposition ensures that the maximand in Program 1 increases from reducing FSQ choices $\mathbf{q}$, e. It follows that every firm will set the lowest level of FSQ in equilibrium.and induce the lowest possible effort level from the auditor.

Proposition 2 shows that if the benefits to funding are large enough, it sets off a "race to the bottom" in terms of FSQ. We now proceed to analyze the effects of introducing FSI. Assume that each firm purchases insurance and that the premiums charged to firms are observable. Suppose now that in equilibrium some firm $f$ sets $\mathbf{q}_{f}<\mathbf{q}_{L}$, where $L$ is the highest type firm. Then, the premium charged to firm $f, \pi_{f}$ is strictly larger than $\pi_{L}$ and investors will infer that firm $f$ is of some type other than $L$. Thus, the inferred rate of return conditioned on observing $\pi_{f}$ will be different from that based on the prior beliefs, $\vec{\nu}$. We will show that the disclosure of $\pi_{f}$ and attendant changes in the inferred rate of return lead to an equilibrium where all firms pool at the highest level of quality, $\bar{q}$.

Two details concerning the relationship between the observed premium, $\pi_{f}$, and the inferred FSQ (and type) of firm $f$ must be cleared up before we can present the equilibrium with FSI. First, based on $\pi_{f}$, investors form posterior beliefs about the firm's FSQ. However, FSQ depends on the choice of both $\mathbf{q}$ and $\mathbf{e}$. We show in our next lemma that a unique level of $\mathbf{e}$ is associated with each level of $\mathbf{q}$. Thus, each probability distribution over $\mathbf{q}$ for firm $f$ (formed after observing $\pi_{f}$ ) corresponds to a unique probability distribution over $\mathbf{x}$; we therefore can describe investor behavior as forming conjectures regarding $\mathbf{x}$ after observing $\pi_{f}$.

\section{Lemma 3 (Investor beliefs regarding FSQ after observing the premium)}

For each level of $\mathbf{q}$, there is a unique optimal level of $\mathbf{e}$, and hence, a unique associated FSQ 
x. Each posterior distribution over the firm's choice of $\mathbf{q}$ after observing $\pi_{f}$ therefore is associated with a unique posterior distribution over FSQ $\mathbf{x}$.

\section{Proof:}

Since $\mathcal{L}_{a}(\mathbf{q}, \mathbf{e})$ is decreasing and convex in $\mathbf{e}$, for each value of $\mathbf{q}$ there is a unique value of e, denoted by $\mathbf{e}^{*}(\mathbf{q})$ that minimizes $C(\mathbf{e})+\mathcal{L}_{a}(\mathbf{q}, \mathbf{e})$. In every program, it can be shown that the level of $\mathbf{e}$ implemented in equilibrium is $\mathbf{e}^{*}(\mathbf{q})$. Further, by our assumption that the marginal reduction in litigation cost decreases in FSQ, that is, the cross-partial of $\mathcal{L}_{a}(\mathbf{q}, \mathbf{e})$ in each q,e is negative (see Section $2.1(2)$ ), the convexity of $C(\mathbf{e})$ implies that $\mathbf{e}^{*}(\mathbf{q})$ is increasing in $\mathbf{q}$. Each level of $\mathbf{q}$ therefore corresponds to the $\operatorname{FSQ} \mathbf{x}(\mathbf{q})=\left\{\mathbf{q}, \mathbf{e}^{*}(\mathbf{q})\right\}$ where $\mathbf{x}(\mathbf{q})$ is increasing in $\mathbf{q}$.

Second, because FSQ is multidimensional but the premium is one-dimensional, we will assume that increasing one dimension of FSQ while holding others constant results in a reduction of the associated premiums. In other words, we assume that if $\mathbf{y} \preceq \mathbf{x}$ then the premium associated with $\mathbf{y}$ is equal to or greater than that associated with $\mathbf{x}$ (with equality only if $\mathbf{y}=\mathbf{x})$. This is consistent with Assumption 2 where the probability of overstatement, and hence the associated liability, decreases as FSQ increases.

We now show formally that the equilibrium in which every firm picks $\bar{q}$ exists under FSI.

\section{Proposition 3 (Equilibrium with Financial Statement Quality Insurance)}

When FSI is made available and premiums are disclosed, the equilibrium in which all firms set $\mathbf{q}_{f}=\overline{\mathbf{q}}$ and the associated $\overline{\mathbf{e}}$ is a rational expectations equilibrium. The expected rate of return on the capital invested by society is increased through the provision of FSI.

\section{Proof:}

Let $\bar{q}$ denote the highest quality choice, $\overline{\mathbf{e}}$ the associated optimal audit intensity and $\bar{\pi}$ the 
resulting break-even premium (see Program II). A rational expectations equilibrium is given by:

(1) Whenever $\pi_{f}=\bar{\pi}$, then $p\left(\omega_{l} \mid \pi_{f}\right)=1 / L$ for every $l$ (in-equilibrium beliefs);

(2) Whenever $\pi_{f}<\bar{\pi}$, then $p\left(\omega_{l} \mid \pi_{f}\right)=\left\{\begin{array}{ll}1 & \text { if } l=1 \\ 0 & \text { if } l>1\end{array}\right.$ (off-equilibrium beliefs);

Under the belief system above, any type paying premium $\pi_{f}>\bar{\pi}$ is perceived as type 1 , and the expected return $E\left[r_{f} \mid \theta_{f}=j, \pi_{f}\right]=E\left[r_{f} \mid \theta_{f}=j, \omega_{1}\right]$ is less than $E\left[r_{f} \mid \theta_{f}=j, \bar{\pi}\right]$. Therefore, the funding probability declines for every report $j$ whenever $\mathbf{q}_{f} \preceq \overline{\mathbf{q}}$ is selected (resulting in a premium $\pi_{f}>\bar{\pi}$ ).

Hence, $F P_{f}\left(\mathbf{q}, \mathbf{e} \mid \pi_{f}\right)<F P_{f}(\overline{\mathbf{q}}, \overline{\mathbf{e}} \mid \bar{\pi}) ;$ in addition, $\pi_{f}>\bar{\pi}$. Deviating to $\mathbf{q}<\overline{\mathbf{q}}$ makes every firm-type worse off so the equilibrium is for all firms to set $\overline{\mathbf{q}}$.

The fact that defections from high quality are detected and immediately penalized results in the "flight to quality" documented in Proposition 3. Specifically, high-type firms gain from setting high FSQ. If low-type firms can muddy investor perceptions through low FSQ, high-type firms are also driven to exaggerate their own outcomes, leading to the result in Proposition 2. In contrast, in Proposition 3, by staying with high FSQ, good firms force others to follow suit or be identified as low types. Thus, low-type firms either abandon their quest for capital or accept a much lower probability of being able to mislead investors in equilibrium.

Although Proposition 3 demonstrates that with FSI, the best possible quality implementation is an equilibrium, we cannot formally rule out all other equilibria. In general, one can obtain economically unintuitive sequential equilibria by specifying implausible offequilibrium beliefs. The standard device to rule out "bad equilibria" is to impose restrictions 
on such off-equilibrium beliefs. In the simple case of two rates of return discussed in the example, a direct proof can be given that "pooling-at-the-top" is the only equilibrium that meets the divinity test.

\section{Proposition 4 (Refinement Test)}

Suppose $L=2$ (as in our example). Then, the equilibrium where all firms pool at the highest level of quality $\mathbf{q}$ is the only one that meets the divinity refinement criterion.

\section{Proof:}

See Appendix 1.

The analysis in this section assumes that the insurance premium is based on the actual level of FSQ chosen by firms. More generally, the insurer relies on the auditor's assessment of FSQ to set the premium. In the next two results, we show that if the auditor reports FSQ strategically in order to maximize his own payoffs, the revelation of the premium to investors does not break the "race to the bottom" with regard to audit quality so long as the auditor functions as an agent of management. That is, firms would prefer to get the auditor to report a higher level of FSQ to the insurance company and thereby to investors than the one that has been chosen. As rational insurers and investors will anticipate this "bias", the equilibrium unravels to the lowest choice of FSQ. In contrast, when the auditor functions as an agent of the insurer, the pooling at the highest quality again becomes the rational equilibrium. We demonstrate this through the next two propositions.

\subsection{Auditing with Moral Hazard}

In this section, we introduce an auditor who has private information about the quality of the reporting system and functions under moral hazard. We emphasize that the moral hazard 
is with regard to reporting the quality of the financial system and not with regard to audit quality, that is, $e$ is contractible, but the quality of the reporting system is not. From the insurer's perspective, the number of hours the auditor actually worked or the rigor of the tests applied to the financial statement are observable and contractible. However, the insurer must rely on the auditor's report regarding the quality of the financial systems implemented by the firm. Under these circumstances, we have to modify Equation (14)as follows. Let $\hat{\mathbf{q}}$ indicate the auditor's report regarding the firm's financial statement quality. We assume that a contractual transfer $\tau(\hat{\mathbf{q}}, \mathbf{q})$ from the auditor to the insurer can be prespecified whenever there is litigation and the true quality $\mathbf{q}$ is revealed. Such a transfer allows the revelation principle to be invoked, and we can define an amount $\hat{F}(\mathbf{q}, \mathbf{e})$ :

\section{Definition 1 (Auditor Compensation)}

$\hat{F}(\mathbf{q}, \mathbf{e})$ is the minimum payment that must be made to induce the auditor to report the true quality as $\hat{\mathbf{q}}=\mathbf{q}$, to supply effort $\mathbf{e}$, and to face the litigation cost $\mathcal{L}_{a}(\mathbf{q}, \mathbf{e})$.

With this definition, the formal program with the auditor as an agent of the insurance company under moral hazard can be stated:

$\underline{\text { Program III }}$

$$
\begin{array}{ll}
\max _{q} & F P_{f}\left(q, e \mid \vec{\nu}_{-f} \vec{\pi}\right) B-\pi_{f} \\
\text { subject to } & \\
& \pi_{f}=\min _{F, \mathbf{e}} L_{f}(\mathbf{q})+\hat{F}(\mathbf{q}, \mathbf{e}) \\
& \nu_{i}=\left\{q_{i}, e_{i}\right\}
\end{array}
$$

The analog of Proposition 3 is straightforward. The proof goes through essentially unchanged implying the following result.

\section{Proposition 5 (Equilibrium with FSI and the Auditor as the Insurer's Agent)} When FSI is made available and premiums are disclosed, there is an equilibrium where all 
firms set $q_{i}=\bar{q}$. In addition, if $L=2$, this is the only equilibrium meeting the divinity criterion.

\section{Proof:}

Program III is virtually identical to Program II - the only difference is the fact that $\hat{F}(\mathbf{q}, \mathbf{e})$ replaces $F(\mathbf{q}, \mathbf{e})$.

To conclude our analysis, we discuss the (hypothetical) situation where the firm purchases financial statement insurance but continues to pay the auditor. Under these circumstance, it is reasonable to ask whether the publicizing the premium will have any beneficial consequences. In other words, what are the consequences if insurance premiums are publicly reported, but the auditor continues as an agent of the firm? If the auditor continues as an agent of the firm, the firm can write forcing contracts. Let $\hat{F}(\hat{\mathbf{q}}, \mathbf{q}, \mathbf{e})$ denote the cost to the firm of getting the auditor to exert effort $\mathbf{e}$ and report the quality as $\hat{\mathbf{q}}$ when the true quality is q. Note that the auditor can be incentivized to reveal the true FSQ but the revelation principle does not apply. The auditor is an agent of the firm and the firm already knows the true FSQ. The real issue is whether the firm can be incentivized to allow the true FSQ to be revealed. This is where the revelation principle breaks down because the market's funding strategies have to be ex-post rational and any form of precommitment is precluded. ${ }^{11}$ In the absence of precommitment to funding schemes, the revelation principle cannot be invoked.

When the auditor continues as an agent of the firm truthful revelation of FSQ may be impossible ex-ante. However, as discussed earlier, litigation will typically reveal the true FSQ. Under these circumstances, the insurer will find it possible to specify a transfer, $\sigma(\hat{\mathbf{q}}, \mathbf{q})$ with the firm (because the insurer has a contractual relationship only with the firm). The key point is that this transfer is made ex-post and will not be known at the time of trading.

\footnotetext{
${ }^{11}$ (See Wilson [3]) for a discussion of the incapacity of markets to precommit to pricing schemes.
} 
Hence the firm does not internalize the cost of the low quality ex-ante. The associated program will be the following:

$\underline{\text { Program IV }}$

$$
\begin{array}{ll}
\max _{\hat{\mathbf{q}}, \mathbf{q}, \mathbf{e}} \quad F P_{f}\left(\mathbf{q}, \mathbf{e} \mid \vec{\nu}_{-f} \vec{\pi}\right) B-\hat{F}(\hat{\mathbf{q}}, \mathbf{q}, \mathbf{e})-\pi_{f}-\sigma(\hat{\mathbf{q}}, \mathbf{q}) \\
\text { subject to } \\
& \pi_{f}=\mathcal{L}_{f}(\hat{\mathbf{q}})+\mathcal{L}_{a}(\hat{\mathbf{q}}, \mathbf{e}) \\
& \sigma(\hat{\mathbf{q}}, \mathbf{q})=\left[\mathcal{L}_{f}(\mathbf{q})-\mathcal{L}_{f}(\hat{\mathbf{q}})\right]+\left[\mathcal{L}_{a}(\hat{\mathbf{q}}, \mathbf{e})-\mathcal{L}_{a}(\hat{\mathbf{q}}, \mathbf{e})\right] \\
& \nu_{i}=\left\{q_{i}, e_{i}\right\}
\end{array}
$$

The initial premium observed by the market (Constraint (IP)) reflects the FSQ reported by the auditor to the insurance company rather than the true FSQ. Under these circumstances, the firm will always have incentives to set low FSQ to increase the probability of funding while incentivizing the auditor to over report the FSQ. Market participants will anticipate this and set funding strategies based on low FSQ precipitating a "race to the bottom," as summarized in our final result.

\section{Proposition 6 (Equilibrium with insurance and with the Auditor as the Firm's Agent)}

Suppose that the benefits to funding, $B$, are very large relative to the penalties for overstatement, $\mathcal{L}$. In addition, suppose that the financial statement quality is unobservable and that the auditor is an agent of the firm. Then the equilibrium quality levels are for every firm to set $\mathbf{q}_{f}=\underline{q}$ where $\underline{q}$ is the minimum permissible level and implement $e=0$. Consequently, capital is allocated to firms with low rate of return with relatively high probability.

\section{Proof:}

As $\hat{F}(\hat{\mathbf{q}}, \mathbf{q}, \mathbf{e})=F(\mathbf{q}, \mathbf{e})$ (because the firm will pay the auditor only if $\hat{\mathbf{q}}$ is reported), Program IV is essentially equivalent to Program I. The only minor difference is that beliefs may be affected by observing the premium. However, firms can costlessly change their initial 
premium by getting the auditor to report the suitable $\hat{\mathbf{q}}$. For this reason, the premium ceases to provide any information and Programs IV and I are essentially equivalent.

\section{Discussion of Results and Implications}

The formal analysis is focused on two salient features of the FSI scheme: disclosure of premiums and changes in the agency relationship with the auditor. In this section, we discuss the implications of the results and the economic features and institutional arrangements that will have to be put in place to facilitate practical implementation. We discuss the implications of the size of insurance coverage, auditor conservatism, and the likelihood of collusion between the audit firm and the insurance carrier.

\subsection{Size of Coverage}

The magnitude of potential liability arising from financial statement misrepresentations is one of the key considerations in the FSI scheme. Are losses stemming from misrepresentations likely to be too large to be covered by insurance companies? We do not think so. Financial statement misrepresentation losses exist in the current regime and are borne in one way or another by several players, including investors, companies (in the form of class action litigation settlements), insurance companies (through D\&O and malpractice underwriting settlements), and the audit firms and the firms themselves through premiums paid on D\&O insurance. The effective "premium" companies and auditors now pay is considerably larger that the nominal premium paid for D\&O or malpractice insurance. In other words, if losses result from accounting irregularities, someone must be bearing them. Hence, all things considered, the cost of recoveries through a combination of D\&O insurance and settlements currently borne by investors in audit failure cases would necessarily be lower when the 
auditor's incentives are aligned with those of investors. Thus, the total premiums needed to accord investors the same level of recovery cannot be greater than they are under the current system. On the contrary, total losses under FSI are likely to be less because of the incentives for companies to minimize their cost of capital, which will induce them to minimize premiums by improving the quality of their financial statements and minimize the loss-causing irregularities. This would be reinforced by the better quality audits. In other words, even keeping the coverage and the extent to which investors' losses are recouped at no more than it is today we would have improved audit quality, mitigated conflict of interest, and more efficient resource allocation.

If companies demand large coverage, our FSI model can be adapted easily to handle this situation. Unlike insuring against non-tradable assets such as personal accidents, building fires and the like, insurers can hedge their exposure in underwriting coverage for securitized assets (equities) by devising suitable straddle strategies to "reinsure" their exposure in capital markets. Under the proposed FSI mechanism, the insurers, who strictly speaking need not in fact be insurance companies, can purchase options to hedge the risks, or better yet, purchase specialized conditional puts, the exercise of which would be triggered by the occurrence of the insured event: misrepresentation or omission. Note, too, that not all companies (and hence securities) carry the same financial statement risk: some are better than others. Hence, there is a possibility of constructing portfolios that are diversified on this dimension of risk: the contribution of one security to the aggregate financial statement risk of the portfolio is less then its own financial statement risk.

\subsection{Auditor Conservatism}

It is tempting to suggest that the FSI scheme might induce an excessive, and harmful, degree of auditor conservatism. This need not be the case. We should point out that class action 
securities litigation can involve sellers who suffer losses resulting from overly conservative statements as well as the typical purchasers' class. The fact that these were fewer in the past merely reflects the fact that companies' incentives are skewed in the direction of inflating, rather than deflating, earnings. The FSI scheme would tend to balance the incentives and induce less bias and greater accuracy in financial statements. If, for example, FSI induces ultra-conservatism, the incidence of sellers' losses will be expected to increase, prompting a higher insurers' expectation of sellers' claims, in turn inducing them to guide the auditors they hire toward emphasis on greater accuracy. Removing the conflict of interest through the FSI scheme will minimize the potentially adverse effects inflicted by the subjectivity that inheres in accounting decisions. As we discuss below, however, a GAAP reform could reinforce the salutary effects of FSI.

\subsection{Collusion between Firm and Insurance Carrier}

Collusion between the company being audited and the insurance company is not plausible under the FSI regime. It may be argued that because the audited firm chooses the FSI carrier out of a list of possible companies, it will be in the interest of the insurance company to offer a premium lower than the competitive rate in order to be selected. The insurance carrier will have to be compensated for the loss by charging an unjustifiably high premium on other policies supplied to the audited company.

Such a carrier faces various adverse consequences. First, the carrier would have to publicize the lower premium as a requirement of the FSI scheme. This would result in a higher price for the stock and higher capitalization, which in turn would increase the losses to shareholders upon an event of omission or misrepresentation. Since the losses are an increasing function of the firm's market capitalization, the more inflated the price, the larger the potential price drop. The expected coverage cost incurred by the insurance carrier within the 
limit of the policy would increase, offsetting any gains from over charging on other services. Second, since the audit report is publicly observed, the audit firm will have to acquiesce in the collusion between the carrier and company being audited for this to work. Third, insurance carriers are subject to a very strict audit by the various regulatory insurance bodies. Too low a premium would invite regulatory scrutiny and the possible establishment of higher reserves, which would impose additional costs on the carrier. Finally, requiring public disclosure of all premiums (on all insurance lines) paid by the FSI-insured would suffice to deter a conspiracy.

\section{Conclusion}

Several causes have been advanced in the media for the recent "accounting" meltdown: irrational exuberance, infectious greed, the stock market bubble, moral turpitude of executives, unethical accountants, non-audit services, and related "ills." We have argued that the inherent conflict of interest in the auditor-client relationship and the unobservability of financial statement quality are the likely culprits. Bubbles and exuberance merely magnify the payoffs so that executives are more tempted to "cook the books" and the auditors' conflict of interest is aggravated. Financial Statement Insurance, as developed here, provides a market-based solution that acts as an effective check on the issuance of overly biased financial statements. First, by transferring the auditor hiring decision to the insurer, FSI eliminates the auditors' inherent conflict of interest. Second, the publication of the insurance coverage and the premium will credibly signal the quality of the insured's financial statements and direct investments toward better projects. At the same time, the ability to signal the quality of financial statements will provide companies with incentives to improve the quality of their financial statements. Hence, FSI will result in fewer misrepresentations and, accordingly, in fewer suits and stakeholder losses. 
Under the present regime, auditors' legal liability is not an effective tool for inducing truth telling in financial statements because the costs of such liability are essentially covered by the clients. As mentioned, the FSI scheme effectively eliminates the conflict of interest that came to light in the aftermath of Enron. Yet financial statement insurance has other important benefits: the credible signaling of financial statement quality and a consequent improvement of such quality, the decrease in shareholder losses, and the better channeling of savings to socially desirable projects. This solution can be complemented and reinforced by GAAP reforms, resulting in significant additional indirect benefits. If implemented, FSI would facilitate an accounting approach based on underlying principles rather than detailed rules, akin to UK GAAP. The current U.S. model encourages corporate officers to view accounting rules as analogous to the Tax Code, with detailed specific rules.

Traditionally, detailed rules have been championed because they enhance credibility. Uniform application decreases the ambiguity of results and variation in reported numbers. Hence, it enhances comparability and possibly decreases audit costs (by minimizing disputes with clients about accounting choices). Yet detailed rules also decrease the flexibility of management in making accounting choices and thus limit its ability to signal expectations about the prospects of the company that are not shared by the public. If discretion is accorded the manager over which accounting methods to apply in a particular instance, he will, if he wishes to report honestly, employ methods that best reflect the "economic reality" of the company. Restricting his choice by imposing detailed rules reduces his ability to convey truthful information if he is so inclined. Along with the flexibility, therefore, incentives should be aligned to elicit truthful information from management. Adopting a "softer" view of GAAP similar to the UK model would allow auditors to report a "true and fair view" of an enterprise rather than merely attesting to whether GAAP rules were followed. Of course, more flexibility can be abused, unless auditors' incentives are properly aligned, as in 
FSI. Hence, FSI facilitates the adoption of a principles approach. The basis for this already exist in the seven concepts that now constitute the FASB's Conceptual Framework. These concepts articulate the objectives of financial statements and offer criteria for measurement and reporting that are designed to satisfy the objectives. 


\section{References}

[1] Grossman, S., (1995) "Dynamic Asset Allocation and the Informational Efficiency of Markets," Journal of Finance, Vol L, No. 3, 773-787.

[2] Ronen J. 8:1, 2002 "Post-Enron Reform: Financial Statement Insurance, and GAAP Re-visited" Stanford Journal of Law, Business \& Finance, 1-30.

[3] Wilson, R., "Auditing: Perspectives from Multiperson Decision Theory," Accounting Review, 1983, pp. 305-349. 


\section{Appendix 1}

\section{Proof of Proposition 4}

Let $\omega_{2}>\omega_{1}$, that is, $p\left(i \mid \omega_{2}\right) / p\left(i \mid \omega_{1}\right)$ is increasing in realized type $i$. Suppose that $\pi_{f}<\bar{\pi}$ and the off-equilibrium beliefs after observing $\pi_{f}$ are such that $\omega_{2}$ is indifferent between choosing $\bar{\pi}$ or $\pi_{f}$. We will show that $\omega_{1}$ would then strictly prefer to choose $\pi_{f}$.

Noting that the lowest report $j=1$ necessarily implies that the firm's rate of return is the lowest possible, $r_{1}, F P\left(j=1 \mid \pi_{f}\right)=F P(j=1 \mid \bar{\pi})=F^{*}\left(r_{1}\right)$. Therefore, denoting the FSQ choice of the $\omega_{2}$ firm by $\mathbf{x}_{f}$, the indifference assumption on $\omega_{2}$ leads to:

$F P\left(1 \mid \pi_{f}\right) p\left(1 \mid \omega_{2} \mathbf{x}_{f}\right)+F P\left(2 \mid \omega_{2}, \pi_{f}\right) p\left(2 \mid \omega_{2}, \mathbf{x}_{f}\right)=F P\left(1 \mid \bar{\pi}, \omega_{2}\right) p\left(1 \mid \omega_{2}, \overline{\mathbf{x}}\right)+F P\left(2 \mid \omega_{2}, \bar{\pi}\right) p\left(2 \mid \omega_{2}, \overline{\mathbf{x}}\right)$

Rearranging and using the facts that: (i) $F P\left(1 \mid \pi_{f}\right)=F P(1 \mid \bar{\pi})=F^{*}\left(r_{1}\right)$ and (ii) $p\left(2 \mid \omega_{j}, \mathbf{x}\right)=$ $1-p\left(1 \mid \omega_{j}, \mathbf{x}\right)$ we obtain:

$$
\begin{aligned}
F P\left(2 \mid \pi_{f}\right) p\left(2 \mid \omega_{2}, \mathbf{x}_{f}\right)-F P(2 \mid \bar{\pi}) p\left(2 \mid \omega_{2}, \overline{\mathbf{x}}\right) & = & F^{*}\left(r_{1}\right)\left[p\left(1 \mid \omega_{2}, \overline{\mathbf{x}}\right)-p\left(1 \mid \omega_{2}, \mathbf{x}_{f}\right)\right] \\
F P\left(2 \mid \pi_{f}\right) p\left(2 \mid \omega_{2}, \mathbf{x}_{f}\right)-F P(2 \mid \bar{\pi}) p\left(2 \mid \omega_{2}, \overline{\mathbf{x}}\right) & = & F^{*}\left(r_{1}\right)\left[p\left(2 \mid \omega_{2}, \mathbf{x}_{f}\right)-p\left(2 \mid \omega_{2}, \overline{\mathbf{x}}\right)\right] \\
\Longleftrightarrow \frac{F P\left(2 \mid \pi_{f}\right) p\left(2 \mid \omega_{2}, \mathbf{x}_{f}\right)-F P(2 \mid \bar{\pi}) p\left(2 \mid \omega_{2}, \overline{\mathbf{x}}\right)}{\left[p\left(2 \mid \omega_{2}, \mathbf{x}_{f}\right)-p\left(2 \mid \omega_{2}, \overline{\mathbf{x}}\right)\right]} & = & F^{*}\left(r_{1}\right) \\
\Longleftrightarrow F P\left(2 \mid \pi_{f}\right)+\frac{\left[F P\left(2 \mid \pi_{f}\right)-F P(2 \mid \bar{\pi})\right] p\left(2 \mid \omega_{2}, \overline{\mathbf{x}}\right)}{\left[p\left(2 \mid \omega_{2}, \mathbf{x}_{f}\right)-p\left(2 \mid \omega_{2}, \overline{\mathbf{x}}\right)\right]} & = & F^{*}\left(r_{1}\right)
\end{aligned}
$$

We note first that as $F P\left(2 \mid \pi_{f}\right)>F P\left(1 \mid \pi_{f}\right)=F^{*}\left(r_{1}\right)$ and $p\left(2 \mid \omega_{2}, \mathbf{x}_{f}\right)>p\left(2 \mid \omega_{2}, \overline{\mathbf{x}}\right)$, Equation

(16) can only hold if $F P\left(2 \mid \pi_{f}\right)<F P(2 \mid \bar{\pi})$. From the fact that $p\left(j \mid \omega_{l}, \mathbf{x}_{f}\right)=\sum_{i} p\left(j \mid i, \mathbf{x}_{f}\right) p\left(i \mid \omega_{l}\right)$, it follows that:

$$
\begin{aligned}
\frac{p\left(2 \mid \omega_{1}, \mathbf{x}_{f}\right)}{p\left(2 \mid \omega_{1}, \overline{\mathbf{x}}\right)} & =\frac{p\left(2 \mid i=2, \mathbf{x}_{f}\right) p\left(i=2 \mid \omega_{1}\right)+p\left(2 \mid i=1, \mathbf{x}_{f}\right) p\left(i=1 \mid \omega_{1}\right)}{p(2 \mid i=2, \overline{\mathbf{x}}) p\left(i=2 \mid \omega_{1}\right)+p(2 \mid i=1, \overline{\mathbf{x}}) p\left(i=1 \mid \omega_{1}\right)} \\
& =\frac{p\left(i=2 \mid \omega_{1}\right)+p\left(2 \mid i=1, \mathbf{x}_{f}\right) p\left(i=1 \mid \omega_{1}\right)}{p\left(i=2 \mid \omega_{1}\right)+p(2 \mid i=1, \overline{\mathbf{x}}) p\left(i=1 \mid \omega_{1}\right)} \\
& =\frac{1+p\left(2 \mid i=1, \mathbf{x}_{f}\right) \frac{p\left(i=1 \mid \omega_{1}\right)}{p\left(i=2 \mid \omega_{1}\right)}}{1+p(2 \mid i=1, \overline{\mathbf{x}}) \frac{p\left(i=1 \mid \omega_{1}\right)}{p\left(i=2 \mid \omega_{1}\right)}}
\end{aligned}
$$


The analogous equation for $\omega_{2}$ yields:

$$
\frac{p\left(2 \mid \omega_{2}, \mathbf{x}_{f}\right)}{p\left(2 \mid \omega_{2}, \overline{\mathbf{x}}\right)}=\frac{1+p\left(2 \mid i=1, \mathbf{x}_{f}\right) \frac{p\left(i=1 \mid \omega_{2}\right)}{p\left(i=2 \mid \omega_{2}\right)}}{1+p(2 \mid i=1, \overline{\mathbf{x}}) \frac{p\left(i=1 \mid \omega_{2}\right)}{p\left(i=2 \mid \omega_{2}\right)}}
$$

Comparing the quantities on the right-sides of Equations (17) and (18)and using the facts :

$$
\frac{p\left(i=1 \mid \omega_{2}\right)}{p\left(i=2 \mid \omega_{2}\right)}<\frac{p\left(i=1 \mid \omega_{1}\right)}{p\left(i=2 \mid \omega_{1}\right)} ; \quad \text { and } \quad p\left(2 \mid i=1, \mathbf{x}_{f}\right)>p(2 \mid i=1, \overline{\mathbf{x}})
$$

we infer that:

$$
\begin{aligned}
\frac{p\left(2 \mid \omega_{1}, \mathbf{x}_{f}\right)}{p\left(2 \mid \omega_{1}, \overline{\mathbf{x}}\right)} & >\frac{p\left(2 \mid \omega_{2}, \mathbf{x}_{f}\right)}{p\left(2 \mid \omega_{2}, \overline{\mathbf{x}}\right)} \\
\Longrightarrow \frac{p\left(2 \mid \omega_{1}, \mathbf{x}_{f}\right)}{p\left(2 \mid \omega_{1}, \overline{\mathbf{x}}\right)}-1 & >\frac{p\left(2 \mid \omega_{2}, \mathbf{x}_{f}\right)}{p\left(2 \mid \omega_{2}, \overline{\mathbf{x}}\right)}-1
\end{aligned}
$$

It follows that:

$$
\begin{aligned}
\frac{p\left(2 \mid \omega_{1}, \mathbf{x}_{f}\right)-p\left(2 \mid \omega_{1}, \overline{\mathbf{x}}\right)}{p\left(2 \mid \omega_{1}, \overline{\mathbf{x}}\right)} & >\frac{p\left(2 \mid \omega_{2}, \mathbf{x}_{f}\right)-p\left(2 \mid \omega_{2}, \overline{\mathbf{x}}\right)}{p\left(2 \mid \omega_{2}, \overline{\mathbf{x}}\right)} \\
\Longrightarrow \frac{p\left(2 \mid \omega_{1}, \overline{\mathbf{x}}\right)}{p\left(2 \mid \omega_{1}, \mathbf{x}_{f}\right)-p\left(2 \mid \omega_{1}, \overline{\mathbf{x}}\right)} & <\frac{p\left(2 \mid \omega_{2}, \overline{\mathbf{x}}\right)}{p\left(2 \mid \omega_{2}, \mathbf{x}_{f}\right)-p\left(2 \mid \omega_{2}, \overline{\mathbf{x}}\right)}
\end{aligned}
$$

Therefore:

$$
\begin{aligned}
F P\left(2 \mid \pi_{f}\right) & +\left[F P\left(2 \mid \pi_{f}\right)-F P(2 \mid \bar{\pi})\right]\left[\frac{p\left(2 \mid \omega_{1}, \overline{\mathbf{x}}\right)}{p\left(2 \mid \omega_{1}, \mathbf{x}_{f}\right)-p\left(2 \mid \omega_{1}, \overline{\mathbf{x}}\right)}\right] \\
& >F P\left(2 \mid \pi_{f}\right)+\left[F P\left(2 \mid \pi_{f}\right)-F P(2 \mid \bar{\pi})\right]\left[\frac{p\left(2 \mid \omega_{2}, \overline{\mathbf{x}}\right)}{p\left(2 \mid \omega_{2}, \mathbf{x}_{f}\right)-p\left(2 \mid \omega_{2}, \overline{\mathbf{x}}\right)}\right] \\
& =F P\left(2 \mid \pi_{f}\right)+\frac{\left[F P\left(2 \mid \pi_{f}\right)-F P(2 \mid \bar{\pi})\right] p\left(2 \mid \omega_{2}, \overline{\mathbf{x}}\right)}{\left[p\left(2 \mid \omega_{2}, \mathbf{x}_{f}\right)-p\left(2 \mid \omega_{2}, \overline{\mathbf{x}}\right)\right]}=F^{*}\left(r_{1}\right)
\end{aligned}
$$

But (20) and (19) together show that:

$$
F P\left(2 \mid \pi_{f}\right) p\left(2 \mid \omega_{1}, \mathbf{x}_{f}\right)-F P(2 \mid \bar{\pi}) p\left(2 \mid \omega_{1}, \overline{\mathbf{x}}\right) \quad>\quad F^{*}\left(r_{1}\right)\left[p\left(2 \mid \omega_{1}, \mathbf{x}_{f}\right)-p\left(2 \mid \omega_{1}, \overline{\mathbf{x}}\right)\right]
$$

This establishes that if the $\omega_{2}$ firm is indifferent between staying at $\bar{\pi}$ or defecting to $\pi_{f}$, the $\omega_{1}$ firm strictly prefers defecting to $\pi_{f}$ and setting FSQ $\mathbf{x}_{f}$ (see Equation (16)). It is of course possible that $\mathbf{x}_{f}$ may not be the best choice of FSQ for $\omega_{1}$ along the $\pi_{f}$ isoquant - but any superior choice would only increase the funding probability (without increasing the cost 
because it also lies on the $\pi_{f}$-isoquant) making it even better to defect to the off-equilibrium

choice $\pi_{f}$. Therefore, by the divinity criterion, only the lowest $\omega$-type actually is believed to be at the off-equilibrium premium $\pi_{f}$, i.e., the equilibrium of Proposition 3 is the only one that meets the divinity off-equilibrium test.

When $L \geq 3$, the uniqueness of the equilibrium in meeting the divinity test can be established if the equilibrium funding probabilities have the following characteristic:

\section{Assumption 3 (Inferences and Quality)}

Let $\vec{\nu}, \vec{\mu}$ denote investor beliefs where $\nu_{k}>\mu_{k}$ for every $k$. That is, under $\vec{\nu}$, investors believe that every firm chooses a higher quality than under $\vec{\mu}$. Then investors are more discriminating under $\vec{\nu}$ than under $\vec{\mu}$ as described below. For any two reports $j \geq k$ the inferred returns satisfy:

$$
E[r \mid j, \vec{\nu}]-E[r \mid k, \vec{\nu}]>E[r \mid j, \vec{\mu}]-E[r \mid k, \vec{\mu}]
$$

The condition in Equation 22 states that under beliefs of uniformly lower quality, the inferred rates of return change less sharply in the report. In other words, if investors believe that FSQ of every firm is lower, they place less reliance on financial reports. This is an intuitive economic condition and ought to hold quite generally. However, the derivation of (22) from the information structure of Assumptions 1 and 2 presents technical difficulties. 


\section{Appendix 2}

\section{The FSI Process}

The FSI underwriting procedure starts with a review of the potential insured. The review is performed, on behalf of the FSI carrier, by an expert risk assessor, who investigates the nature of conditions such as the following:

- The nature, stability, degree of competition, and general economic health of the industries in which the potential insured operates.

- The reputation, integrity, operating philosophy, financial state, and prior operating results of the potential insured's management.

- The nature, age, size, and operating structure of the potential insured.

- The potential insured's control environment and significant management and accounting policies, practices, and methods.

The process involves five sequential steps:

Step 1-The potential insured requests an insurance proposal from the FSI carrier. The proposal contains, at a minimum, the maximum amount of insurance being offered and the related premium. Typically, it also specifies a schedule of amounts of coverage below the maximum along with associated premiums. The proposal request is made prior to the preparation of the potential insured's shareholders' proxy on the basis of the underwriting review described above. The reviewer can be the same auditor who will eventually audit the financial statements.

Step 2-The proxy offers the following alternatives:

- The maximum amount of insurance and related premium as offered in the insurance proposal.

○ The amount of insurance and related premium recommended by management.

- No insurance

Step 3-If either of the insurance options set forth in Step 2 is approved, then the reviewer and the auditor cooperatively plan the scope and depth of the audit to be conducted. 
Step 4-If, after the audit, the auditor is in the position of rendering a clean opinion, the policy is issued. That is, the originally proposed coverage and premium will be binding on the insurance carrier if the auditor's opinion turns out to be clean. If the auditor's opinion is qualified the insurer will not provide any coverage unless the company can then renegotiate different terms with the insurer, which would depend on the auditor's findings and reasons for qualification. To the extent the policy terms are renegotiated, the new agreedupon terms would be publicized.

Step 5-The auditor's opinion will contain a paragraph disclosing the amount of insurance that covers the accompanying financial statements and the associated premium.

Figure 1 below depicts the sequence of the steps required in the implementation and Figure 2 shows the inter-relationships among the various parties participating in the insurance mechanism and the roles they play. 
Figure 1

The FSI Process

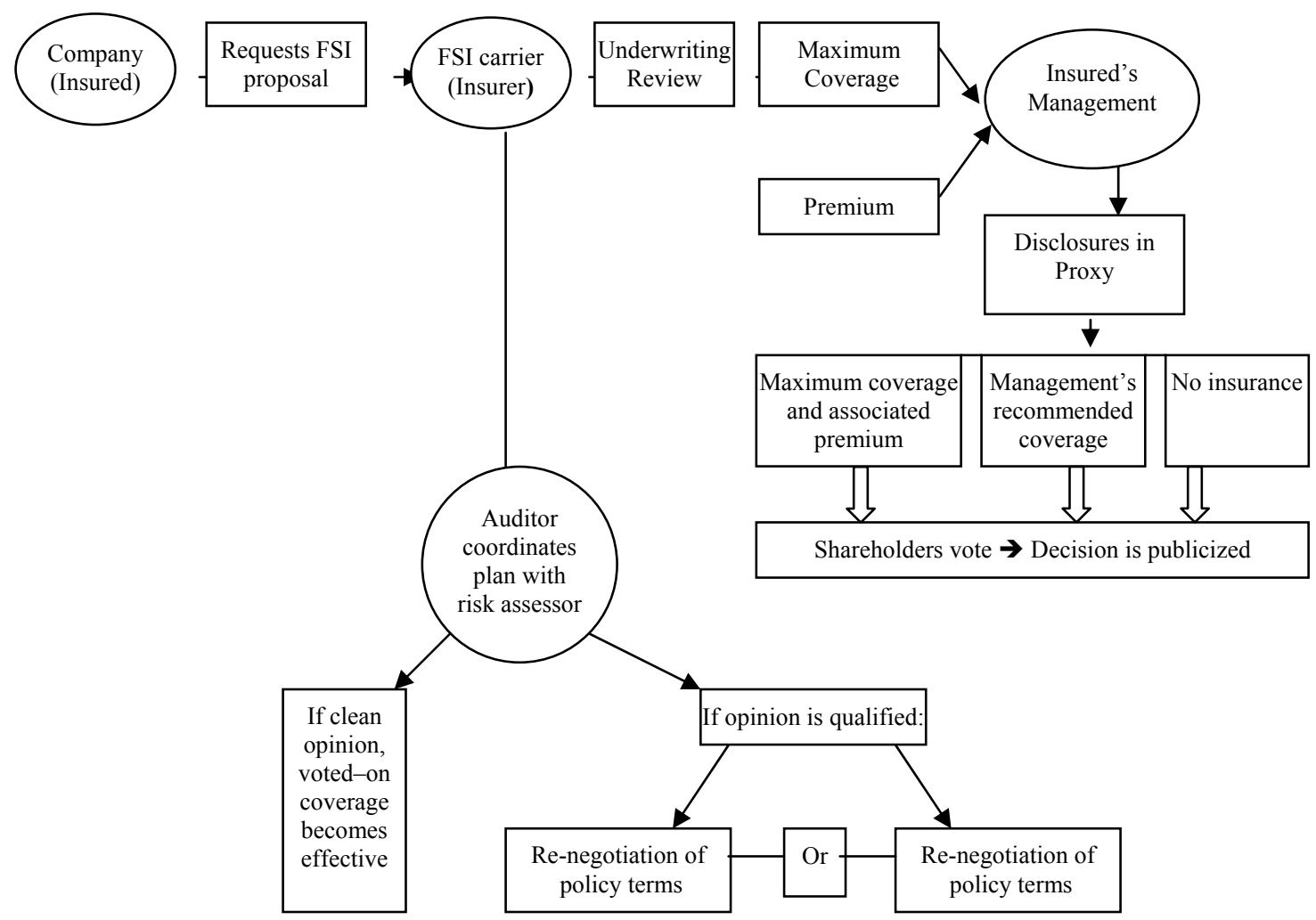


Figure 2

Relationships Among the Parties

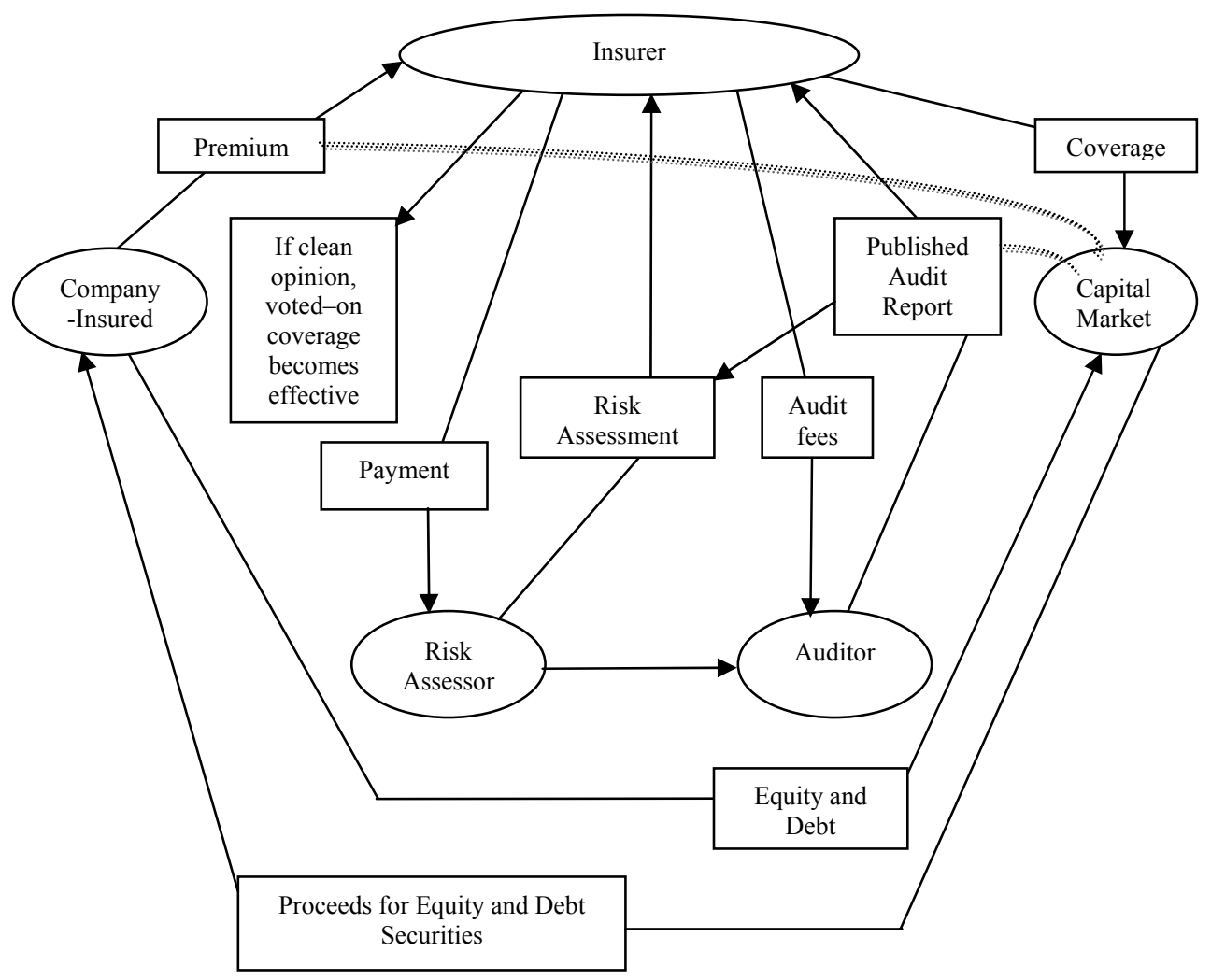

Legend

Solid lines indicate actual flows

Fuzzy lines indicate information flows 